\title{
Review of the Prevention of the Hepatitis B Virus Infection Transmission From Mother to Child During Pregnancy
}

\author{
Seyed Mohammad Hashemi-Shahri ${ }^{1}$; Batool Sharifi-Mood ${ }^{1, *}$; Manijeh Khalili ${ }^{2}$ \\ ${ }_{1}^{1}$ Infectious Diseases and Tropical Medicine Research Center, Zahedan University of Medical Sciences, Zahedan, IR Iran \\ ${ }^{2}$ Children and Adolescents Health Research Center, Aliebn-E-Abitaleb Hospital, Zahedan University of Medical Sciences, Zahedan, IR Iran \\ ${ }^{*}$ Corresponding author: Batool Sharifi-Mood, Infectious Diseases and Tropical Medicine Research Center, Zahedan University of Medical Sciences, Zahedan, IR Iran. Tel:+98-5413228101, \\ Fax:+98-5413236722, E-mail: batoolsharifimood@yahoo.com
}

Received: January 2, 2015; Accepted: January 14, 2015

\begin{abstract}
Context: The hepatitis B virus (HBV) is a highly infectious virus which spreads through blood and other infected fluids such as semen. Individuals can be infected with the virus through sexual contact, by sharing needles or by a needle accident, by getting a body piercing or tattooing, and prenatally or at birth, if the mother is infected with the virus.

Evidence Acquisition: We searched medical databases (namely PubMed and Scopus) from January 2000 to January 2015. Keywords were epidemiology, transmission routes, and prevention of infection during pregnancy.

Results: On the basis of our results, the transmission of the HBV from the infected mother to her child during pregnancy is an important way for the acquisition of the virus. The routine vaccination of neonates and the use of immunoglobulin at birth are very effective for the prevention of infection, when a mother is infected. Also, the treatment of the infected mother to decrease the viral load is another preventive method for the protection of her child.

Conclusions: Our study showed that routine vaccination in children and screening of pregnant women for the HBV infection and then preventative strategies for neonates are the most important routes for minimizing the transmission of infection from mother to child.

Keywords: Hepatitis B; Pregnancy; Prevention
\end{abstract}

\section{Context}

Worldwide, the hepatitis B virus (HBV) is carried by more than 360 million people, many of whom do not even exhibit any symptoms. Mother-to-child transmission can occur during pregnancy and at birth (1-3). When a healthcare practitioner finds that a mother is a carrier, it will allow her physician to treat her baby immediately after delivery to prevent infection. Mother-to-child transmission is responsible for about one-third of chronic HBV infections in the world (4-8). Screening of all pregnant women for the HBV infection enables the physician to perform infant post-exposure prophylaxis and also treat the infected mother with specific antiviral drugs, which are the most important strategies for reducing the transmission rates and the global burden of a new HBV infection $(1,2,9,10)$. When a pregnant woman refers for the first prenatal visit, the physician will give her a series of routine blood tests, including one test for the presence of the hepatitis B surface antigen ( $\mathrm{HBsAg}$ ), which can cause severe liver damage and hepatocellular carcinoma when the child becomes infected during infancy. If the mother is infected, the physician will recommend a dose of hepatitis B immunoglobulin (HBIG) for her baby immediately after birth to protect her child from infection in the short term $(1,2,11-16)$. Neonates should also receive the first dose of the HBV vaccine within 12 hours of birth so as for them to be able to receive the second and third doses of this vaccine at a regular time. All three doses are necessary for lifelong protection against the HBV infection, and the centers for disease control and prevention (CDC) recommends that all babies receive them. Together, the antibodies and the HBV vaccine are about 90\% effective for the prevention of the HBV infection in babies (15-20). Cesarean sections and vaginal deliveries are safe for the HBV-infected mothers. A mother who is infected with the HBV can breastfeed her infant, but she should protect her nipples from cracking and bleeding $(1,2,18-20)$. There are many reports about the rate of the transmission of the HBV infection during pregnancy and also understanding of the mechanisms of the transmission of the infection from mother to child. All these studies have sought to implement policies on maternal screening and infant follow-up as well as mechanisms to minimize the transmission rate (11-23). Here, we aimed to review the ways for the prevention of this infection from mother to child and research the new guidelines.

\section{Evidence Acquisition}

We searched medical databases (namely PubMed and

Copyright (C) 2015, Infectious Diseases and Tropical Medicine Research Center. This is an open-access article distributed under the terms of the Creative Commons Attribution-NonCommercial 4.0 International License (http://creativecommons.org/licenses/by-nc/4.0/) which permits copy and redistribute the material just in noncommercial usages, provided the original work is properly cited. 
Scopus) from January 2000 to January 2015. Keywords were epidemiology, transmission routes, and prevention of infection during pregnancy.

\section{Results}

We found many papers on the transmission of the HBV and also the relevant preventive methods; however, we focused on transmission and prevention routes during pregnancy.

\subsection{Transmission}

Mother-to-child transmission occurs in 5\% - 15\% of infants in the absence of specific prophylaxis $(1,4,10)$. The rate of infection in neonates is associated with the viral load in mothers and having a positive test for e antigen ( $\mathrm{HBeAg}$ ). In mothers who are seropositive for both HBsAg and $\mathrm{HBeAg}$, vertical transmission can occur at an approximate rate of $90 \%(1,2,4,10)$. In women with acute hepatitis $\mathrm{B}$, vertical transmission happens in up to $10 \%$ of neonates when infection arises in the first trimester of pregnancy and in $80 \%$ - 90\% of neonates when acute infection occurs in the third trimester. It has been reported that mothers with HBV DNA levels $\geq 10^{6}$ copies $/ \mathrm{mL}$ ( $>200,000 \mathrm{IU} / \mathrm{mL}$ ) are at greatest risk for the transmission of the HBV to their infants $(2,4,10)$.

\subsection{Prevention}

During 2005, the CDC recommended the advisory committee on immunization practices (ACIP) and all healthcare professionals to administer the HBV vaccine to all newborns before hospital discharge in order to protect them against the HBV infection. Additionally, they should find all infants whose mothers are HBsAg positive or have unknown HBsAg status to administer appropriate prophylaxis to their infants $(4,16-18)$.

\subsubsection{For a Pregnant Woman with a Positive HBsAg Test in Her Prenatal Records, the Physician Must do the Fol- lowing:}

A- Give her a test again to verify that the testing date is during this pregnancy not a previous one.

B- Put a copy of the original HBsAg laboratory report into the infant and pregnant woman's laboratory records.

C- If the pregnant woman is HBsAg positive, alert the nursery staff to the fact that the newborn is at high risk for the HBV infection and will need post-exposure prophylaxis (both HBIG and HBV vaccine). The neonate should receive $\mathrm{HBIG}$ ( $0.5 \mathrm{~mL}$, IM) and single-antigen $\mathrm{HBV}$ vaccine (0.5 mL, IM) at separate injection sites within 12 hours of birth. Any infant with a weight $<2 \mathrm{~kg}(4.4 \mathrm{lb})$ whose mother is HBsAg positive should receive the first dose of the HBV vaccine and HBIG within 12 hours of birth. This dose of the HBV vaccine should not be counted as the first dose in the vaccine series. Healthcare practitioners must reinitiate the full series of the $\mathrm{HBV}$ vaccine at age 1 - 2 months. Inform the medical team of the newborn's birth on the importance of additional on-time vaccination and post-vaccination testing of the infant for HBsAg and antibody to HBsAg after the completion of the HBV vaccine series. The medical team should recommend the following items to the mother $(1,2,19-22)$ :

A- She can breastfeed her infant after delivery, even before the HBV vaccine and HBIG are given.

B- It is critical for her infant to complete the full HBV vaccine series on the recommended schedule.

C- Blood samples should be obtained from her child after the completion of at least three doses of the HBV vaccine series at age 9 - 18 months to determine if the child has developed a protective immune response to vaccination or needs additional management.

D- The mother needs to know about the routes of the $\mathrm{HBV}$ transmission and protection and the need for the testing as well as the vaccination of susceptible sexual and household contacts and needle-sharing contacts.

E- She needs to undergo a medical evaluation for chronic hepatitis B aimed at determining whether she is a candidate for antiviral therapy.

There is evidence that antiretroviral drugs such as Lamivudine, Tenofovir, and Telbivudine can prevent vertical transmission when administered to women with a high HBV viral load in the third trimester (23-38). It has been reported that mothers who have a viral load more than HBV DNA levels $\geq 10^{6}$ copies/mL are at greatest risk for the transmission of the HBV to their infants. Therefore, the physician should recommend them to take anti-viral drugs such as Tenofovir during the third trimester to minimize the risk of the transmission of the infection to their child.

\subsubsection{For a Pregnant Woman Who Does not Have an} HBsAg Lab Report in Her Prenatal Record, Do the Following:

Carry out a repeat blood test for HBsAg if the pregnant woman has a negative test for HBsAg during a prenatal visit but she is at risk for acquiring the HBV infection during this pregnancy because, for instance, she currently uses or has recently used injection drugs; she has an HBsAg-positive sex partner; or she is on evaluation or treatment for a sexually transmitted disease or another risk factor for the HBV infection $(1,2,10)$.

\subsubsection{For the Newborn of an HBsAg-Negative Mother, Do the Following:}

A. Administer a dose of the HBV vaccine $(0.5 \mathrm{~mL}$, IM) before hospital discharge to all newborns weighing $\geq 2 \mathrm{~kg}$ at birth.

B. Give the mother an immunization record card bearing the date of the HBV vaccination.

C. Advise the mother to complete the HBV vaccine se- 
ries to protect her baby against the virus and remind her to bring the immunization record card each time she brings her baby to the clinic $(1,2,18-20)$

\subsubsection{For the Newborn of a Mother with Unknown HB- sAg Status, Do the Following:}

A. Administer a dose of the $\mathrm{HBV}$ vaccine $(0.5 \mathrm{~mL}, \mathrm{IM})$ within 12 hours of birth. The physician should not wait for the test results to return before giving this dose of vaccine.

B. Confirm that the laboratory has received the blood sample for the mother's HBsAg test. If the nursery does not receive the report of the mother's HBsAg test at the expected time, call the laboratory for the result.

C. If the laboratory test shows that the mother is positive for HBsAg, the physician should administer HBIG ( 0.5 $\mathrm{mL}, \mathrm{IM}$ ) to the newborn. It should be injected during the first week after the birth. If more than 7 days have elapsed since birth, administering HBIG to the newborn has little benefit (19-22).

D. If the newborn and mother should be discharged, you must take all contact information for follow-up (i.e. addresses, telephone numbers, and emergency contacts).

\subsection{Post-Exposure Prophylaxis for Susceptible Pregnant Women}

After exposure to persons with acute Hepatitis B: When exposure has happened as a result of sexual contact, within 14 days after the recent sexual contact, the physician should administer a course of the HBV vaccine as soon as possible. Also, the mother should receive one dose of HBIG at a dose of $0.06 \mathrm{~mL} / \mathrm{kg}$ IM into the contralateral arm (14-16). For prophylaxis after a percutaneous or mucous membrane injury, it is recommended that a second dose of HBIG be injected one month later.

\section{Conclusions}

Universal screening of all pregnant women for the HBV infection is the most important and effective factor for the prevention of the transmission of the HBV infection from mother to child. Education about the importance of administering the birth dose of the vaccine within 12 hours of birth is vital. Using antiviral drugs such as Lamivudine, Tenofovir, and Telbivudine can prevent vertical transmission when administered to women with a high HBV viral load in the third trimester. Research is being carried out to develop a vaccine suitable for non-responders to the currently available vaccine.

\section{Authors' Contributions}

All authors had an equal role in the writing of the paper.

\section{References}

1. Nelson NP, Jamieson DJ, Murphy TV. Prevention of Perinatal Hep- atitis B Virus Transmission. J Pediatric Infect Dis Soc. 2014;3(Suppl 1):S7-S12.

2. Geeta MG, Riyaz A. Prevention of mother to child transmission of hepatitis B infection. Indian Pediatrics. 2013;50(2):189-92.

3. Ansari-Moghaddam A, Ostovaneh MR, Sharifi Mood B, SaneiMoghaddam E, Modabbernia A, Poustchi H. Seroprevalence of Hepatitis B Surface Antigen and Anti Hepatitis C Antibody in Zahedan City, Iran: A Population-Based Study. Hepat Mon. 2012;12(9).

4. Lavanchy D. Hepatitis B virus epidemiology, disease burden, treatment, and current and emerging prevention and control measures. JViral Hepat. 2004;11(2):97-107.

5. Kaykhah F, Kouhpayeh HR, Metanat M, Khademi R. Prevalence of Hepatitis B Surface Antigen in Pregnant Women in Zahedan, Iran. Hepat Mon. 2004;4(8):161-3.

6. Sharifi-Mood B, Metanat M, Sanei-Moghaddam E, Khosravi S Comparison of Prevalence of Hepatitis B Virus Infection in Non Official Barbers with Blood Donors. J Med Sci (Faisalabad). 2006;6(2):222-4.

7. Sharifi-Mood B, Eshghi P, Sanei-Moghaddam E, Hashemi M. Hepatitis $B$ and $C$ virus infections in patients with hemophilia in Zahedan, southeast Iran. Saudi Med J. 2007;28(10):1516-9.

8. Sharifi-Mood B, Alavi-Naini R, Salehi M, Hashemi M, Rakhshani F. Spectrum of clinical disease in a series of hospitalized HIV-infected patients from southeast of Iran. Saudi Med J. 2006;27(9):1362-6.

9. Alavian SM, Hajarizadeh B, Ahmadzad-Asl M, Kabir A, BagheriLankarani K. Hepatitis B Virus infection in Iran: A systematic review. Hepat Mon. 2008;8(4):281-94.

10. World Health Organization . Hepatitis B. World Health Organization Fact Sheet 204 (Revised October 2000).. Available from: http:/l who.int/inf-fs/en/fact204.html..

11. Xu WM, Cui YT, Wang L, Yang H, Liang ZQ, Li XM, et al. Lamivudine in late pregnancy to prevent perinatal transmission of hepatitis $B$ virus infection: a multicentre, randomized, double-blind, placebo-controlled study. J Viral Hepat. 2009;16(2):94-103.

12. Dwivedi M, Misra SP, Misra V, Pandey A, Pant S, Singh R, et al. Seroprevalence of hepatitis $\mathrm{B}$ infection during pregnancy and risk of perinatal transmission. Indian J Gastroenterol. 2011;30(2):66-71.

13. Willis BC, Wortley P, Wang SA, Jacques-Carroll L, Zhang F. Gaps in hospital policies and practices to prevent perinatal transmission of hepatitis B virus. Pediatrics. 2010;125(4):704-11.

14. Mast EE, Margolis HS, Fiore AE, Brink EW, Goldstein ST, Wang $\mathrm{SA}$, et al. A comprehensive immunization strategy to eliminate transmission of hepatitis B virus infection in the United States: recommendations of the Advisory Committee on Immunization Practices (ACIP) part 1: immunization of infants, children, and adolescents. MMWR Recomm Rep. 2005;54(RR-16):1-31.

15. Jin H, Zhao Y, Tan Z, Zhang X, Zhao Y, Wang B, et al. Immunization interventions to interrupt hepatitis $B$ virus mother-to-child transmission: a meta-analysis of randomized controlled trials. BMC Pediatr. 2014;14(1):307.

16. Piñeiro C, Fernandes S, Figueiredo C, Sofia Santos A, Moucho $M$, Serrão R, et al. Prevention of mother-to-child transmission: experience of a Portuguese centre. Journal Int AIDS Soc. 2014;17(4(Suppl 3)).

17. Poovorawan Y, Sanpavat S, Pongpunglert W, Chumdermpadetsuk S, Sentrakul P, VandepapeliÊRe P, et al. Long term efficacy of hepatitis B vaccine in infants born to hepatitis B e antigen-positive mothers. Pediatric Infect Dis J. 1992;11(10):816-21.

18. Wen WH, Chang MH, Chen HL. Reply to: Mother-to-infant transmission of hepatitis B virus infection: Significance of maternal viral load and strategies for intervention. J Hepat. 2013;59(2):401.

19. Chen HL, Lin LH, Hu FC, Lee JT, Lin WT, Yang YJ, et al. Effects of maternal screening and universal immunization to prevent mother-to-infant transmission of HBV. Gastroenterology. 2012;142(4):773-781 e2.

20. Ranger-Rogez S, Denis F. Hepatitis B mother--to--child transmission. Expert Rev Anti Infect Ther. 2004;2(1):133-45.

21. Rumi MA, Begum K, Hassan MS, Hasan SM, Azam MG, Hasan KN, et al. Detection of hepatitis B surface antigen in pregnant women attending a public hospital for delivery: implication for vaccination strategy in Bangladesh. Am J Trop Med Hyg. 1998;59(2):318-22. 
22. Shi Z, Li X, Ma L, Yang Y. Hepatitis B immunoglobulin injection in pregnancy to interrupt hepatitis B virus mother-to-child transmission-a meta-analysis. Int J Infect Dis. 2010;14(7):e622-34.

23. Jackson V, Ferguson W, Kelleher TB, Lawless M, Eogan M, Nusgen $\mathrm{U}$, et al. Lamivudine treatment and outcome in pregnant women with high hepatitis B viral loads. Eur J Clin Microbiol Infect Dis. 2015;34(3):619-23.

24. Ehrhardt S, Xie C, Guo N, Nelson K, Thio CL. Breastfeeding While Taking Lamivudine or Tenofovir Disoproxil Fumarate: A Review of the Evidence. Clin Infect Dis. 2014;60(2):275-8.

25. Wu Q, Huang H, Sun X, Pan M, He Y, Tan S, et al. Telbivudine Prevents Vertical Transmission of Hepatitis B Virus From Women With High Viral Loads: A Prospective Long-Term Study. Clin Gastroenterol Hepat. 2015;13(6):1170-6.

26. Tsai PS, Chang A, Yamada S, Tsai N, Bartholomew ML. Use of Tenofovir Disoproxil Fumarate in Highly Viremic, Hepatitis B MonoInfected Pregnant Women. Digestive Dis Sci.2014;59(11):2797-803.

27. Nguyen V, Tan PK, Greenup AJ, Glass A, Davison S, Samarasinghe D, et al. Anti-viral therapy for prevention of perinatal HBV transmission: extending therapy beyond birth does not protect against post-partum flare. Alimentary Pharm Ther. 2014;39(10):1225-34.

28. Zhang H, Pan CQ, Pang Q, Tian R, Yan M, Liu X. Telbivudine or lamivudine use in late pregnancy safely reduces perinatal transmission of hepatitis B virus in real-life practice. Hepatol. 2014;60(2):468-76.

29. Celen MK. Efficacy and safety of tenofovir disoproxil fumarate in pregnancy for the prevention of vertical transmission of HBV infection. WJ Gastroenterol. 2013;19(48):9377.

30. Marcellin P, Heathcote EJ, Buti M, Gane E, de Man RA, Krastev Z, et al. Tenofovir disoproxil fumarate versus adefovir dipivoxil for chronic hepatitis B. N Engl J Med. 2008;359(23):2442-55.
31. Heathcote EJ, Marcellin P, Buti M, Gane E, De Man RA, Krastey $Z$, et al. Three-year efficacy and safety of tenofovir disoproxil fumarate treatment for chronic hepatitis B. Gastroenterology. 2011;140(1):132-43.

32. Shi Z, Yang Y, Ma L, Li X, Schreiber A. Lamivudine in late pregnancy to interrupt in utero transmission of hepatitis B virus: a systematic review and meta-analysis. Obstet Gynecol. 2010;116(1):147-59.

33. Purdy JB, Gafni RI, Reynolds JC, Zeichner S, Hazra R. Decreased bone mineral density with off-label use of tenofovir in children and adolescents infected with human immunodeficiency virus.J Pediatr. 2008;152(4):582-4.

34. Giles M, Visvanathan K, Sasadeusz J. Antiviral therapy for hepatitis B infection during pregnancy and breastfeeding. Antivir Ther 2011;16(5):621-8.

35. Nurutdinova D, Onen NF, Hayes E, Mondy K, Overton ET. Adverse effects of tenofovir use in HIV-infected pregnant women and their infants. Ann Pharmacother. 2008;42(11):1581-5.

36. Mi LJ, Karsdon J, Huang WM, Zhang J, Manheimer F, Tran TT, et al., editors. Outcomes of eight Chinese-Americans pregnant patients with chronic hepatitis B (CHB) treated with tenofovir DF (TDF) during pregnancy.; Hepatol.; 2010; WILEY-BLACKWELL COMMERCE PLACE, 350 MAIN ST, MALDEN 02148, MA USA; p. 505A

37. Tarantal AF, Castillo A, Ekert JE, Bischofberger N, Martin RB. Fetal and maternal outcome after administration of tenofovir to gravid rhesus monkeys (Macaca mulatta). J Acquir Immune Defic Syndr. 2002;29(3):207-20.

38. Gafni RI, Hazra R, Reynolds JC, Maldarelli F, Tullio AN, DeCarlo E, et al. Tenofovir disoproxil fumarate and an optimized background regimen of antiretroviral agents as salvage therapy: impact on bone mineral density in HIV-infected children. Pediatrics. 2006;118(3):e711-8. 